\title{
Aplikasi Pemasaran Otak-Otak Kering Menggunakan Strategi Marketing Mix Berbasis Android
}

\author{
Vistia Herlianti ${ }^{1}$, Karpen ${ }^{2}$ \\ ${ }^{1,2}$ Program Studi Teknik Inforatika STMIK Amik Riau \\ Jl. Purwodadi Indah Km. 10 Panam Pekanbaru Telp. 0761-589561 \\ e-mail : ${ }^{1}$ vistia_herlianti@gmail.com, ${ }^{2}$ karpen@ $@$ stmik-amik-riau.ac.id
}

\begin{abstract}
Abstrak
Otak-otak kering merupakan salah satu makanan khas Provinsi Riau yang cukup banyak di gemari oleh kalangan masyarakat untuk di jadikan oleh-oleh atau cemilan hari-hari. Salah satu tempat produksi otak-otak kering ini yaitu homemade tidak mempunyai sistem untuk menjangkau konsumen dalam wilayah yang lebih luas, serta sistem pemasaran dan pemesanan yang manual membuat konsumen kesusahan mencari alamat produksinya. Oleh karena itu perlu di buat sebuah aplikasi sistem yang dapat membantu usaha ini agar lebih efektif dan efisien dalam pemasaran dan costumer support, yaitu dengan menerapan Strategi Marketing Mix (Berbaur Pemasaran) yang meliputi Product, Price, Promotion, dan Place. Adanya sistem yang berbasiskan Android ini, diharapkan dapat lebih meningkatkan pelayanan terhadap pelanggan dan pemasaran serta jangkauan konsumen menjadi luas, mudah dan bisa dilakukan kapan dan dimana saja.
\end{abstract}

Kata kunci : Otak-otak kering, Aplikasi, Strategi Marketing Mix, Android.

\begin{abstract}
Dry brains are one of the typical foods of Riau Province which is enjoyed by the community forsouvenirs or snacks of the day. One of the production sites of these dry brains, namely homemade does not have a system to reach consumers in a wider area, and manual marketing and ordering systems make it difficult for consumers to find their production address. Therefore it is necessary to create a system application that can help this business to be more effective and efficient in marketing and customer support, namely by applying the Marketing Mix Strategy which includes Product, Price, Promotion, and Place. The existence of this system application based on Android is expected to be able to further improve services to customers and marketing as well as the reach of consumers to be broad, easy and can be done anytime and anywhere.
\end{abstract}

Keywords: Dry brain, Application, Marketing Mix Strategy, Android

\section{Pendahuluan}

Sampai saat ini Indonesia memiliki 1.128 suku bangsa di mana setiap bangsa memiliki budaya masing-masing, salah satunya adalah budaya kuliner. Jumlah kuliner nusantara yang sangat banyak ini dapat dilihat dari jumlah usaha di bidang kuliner. Tercatat pada tahun 2009 terdapat 2.704 usaha kuliner di Indonesia dengan pertumbuhan mencapai 20,98\%. [1]. Data tersebut menjelaskan bahwa bisnis kuliner merupakan salah satu bisnis yang paling menjanjikan di Indonesia. Salah satunya sebuah usaha Reza homemade yang menyediakan produk makanan yaitu Otak-Otak Kering yang berada di kota Pekanbaru. Produk makanan ini sebagai cemilan sehari-hari dan sekaligus sebagai oleh-oleh. Makanan ini berbahan dasar ikan gabus yang aman dikonsumsi serta tanpa bahan pengawet dan pewarna buatan serta diolah dengan bahan-bahan yang higenis dan halal. 
Usaha Reza Homemade, merupakan tempat produksi makanan khas Pekanbaru yaitu otak-otak kering yang berlokasi di jalan Taman Karya Gang arafah no. 9 Panam Pekanbaru. Selama ini usaha yang dilakukan dalam memasarkan produknya masih menggunakan informasi dari mulut ke mulut juga melalui instagram, via telephone dan datang langsung ke tempat produksi. Sistem pemasaran dengan cara ini masih menyulitkan sebahagian masyarakat dalam memperoleh produk otak-otak kering ini. Adanya kemajuan teknologi dan merebaknya pemanfaatan internet memberi jalan mulus bagi promosi usaha, seperti pemanfaatan aplikasi yang berbasis Android sebagai sarana untuk memasarkan usaha melalui internet yang lebih mudah di akses serta memudahkan konsumen [2]

Sebuah sistem yang dapat menjembatani antara konsumen dengan hasil produk Reza Homemade, dirancang sebagai media untuk promosi yang dapat di akses dan mudah dikenali oleh masyarakat luas. Salah satu jalan adalah dengan membuat sebuah aplikasi pemasaran [3] mengenai produk otak-otak kering ini, dengan tujuan untuk memudahkan para konsumen atau masyarakat dalam mendapatkan informasi mengenai produk otak-otak kering, baik online maupun datang ke tempat produksi. Untuk mendukung pemasaran produk tersebut, maka perlu adanya strategi yang tepat yaitu dengan strategi Marketing Mix atau disebut juga dengan strategi berbaur pemasaran [4] . Selain itu pemasaran yang dilakukan dan juga promosi akan lebih luas karena bisa dilihat dan diakses di internet tanpa dibatasi dengan jarak dan waktu serta bisa dilakukan kapan dan dimana saja [5].

Perumusan masalah yang diangkat dalam penelitian ini adalah bagaimana merancang aplikasi pemasaran otak-otak kering menggunakan strategi Marketing Mix berbasis Android. Adanya aplikasi pemasaran ini diharapkan dapat : 1). menjadi sebuah referensi atau masukkan bagi penerapan strategi marketing mix dalam mempromosi produknya seperti makanan, 2). Sistem yang dibangun dapat mempermudah kinerja pemilik produk otak-otak kering baik itu dalam pemasaran dan pemesanan, 3). Sistem ini menjembatani konsumen (masyarakat) untuk lebih mudah memesan, mendapatkan, dan membayar produk yang dibelinya, baik secara transfer (on line) yang dapat di akses hanya dari handphone dan bisa di kirimkan langsung tanpa harus ketempat produksinya, 4). Memudahkan akses dalam pemasaran dan pengenalanan produk otak-otak kering kepada masyarakat luas, baik secara nasional maupun internasional.

\section{Metode Penelitian}

Metode penelitian yang digunakan dalam penelitian ini terdiri dari beberapa tahapan, yaitu tahap melakukan pengumpulan data, sebagai tahap awal untuk mengumpulkan sejumlah data-data yang berhubungan dengan masalah penelitian. Selanjutnya tahap analisa data, dimana tahapan ini menjelaskan mengenai sistem yang berjalan selama ini, dan tahap perancangan sistem, yang meliputi perancangan sistem aplikasi pemasaran global dan detail.

\subsection{Pengumpulan Data}

1. Jenis Data

a. Data Primer yaitu data yang diperoleh melalui observasi maupun wawancara langsung di lapangan. Data primer tersebut diperoleh dari Reza Homemade, yang berupa data otak-otak kering yang meliputi Product, Price, Promotion, dan Place.

b. Data sekunder adalah data yang diperoleh peneliti secara tidak langsung, tanpa melakukan survey maupun pengamatan langsung. Data sekunder diperoleh dari sumber-sumber jurnal atau prosiding serta penelitian-penelitian sebelumnya yang terkait dengan pembahasan tentang penerapan Strategi Mix (Barbaur Pemasaran) yang berbasis android [8].

2. Sumber Data

Sumber data dalam penelitian ini diperoleh dari pihak pemilik Reza Homemade

3. Pengumpulan Data

Pengumpulan data dilakukan dengant tiga cara yaitu: 
a. Metode Observasi adalah metode pengumpulan data yang dilakukan dengan cara melakukan pengamatan langsung kelapangan mengenai permasalahan yang ditemui, yaitu di Reza Homemade jl. Taman Karya Gang Arafah no 9, Pekanbaru, Riau.

b. Wawancara, metode wawancara adalah metode pengumpulan data yang dilakukan dengan cara melakukan wawancara (tanyajawab) dengan pihak yang berhubungan dengan permasalahan yang ditinjau. Wawancara dilakukan dengan pemilik Reza Homemade yaitu ibu Fitri Susanti.

c. Tinjauan Pustaka, dilakukan pengambilan data, mencari dan memahami bahanbahan pustaka terkait dengan strategi Marketing Mix (Berbaur Pemasaran).

\subsection{Analisa Data}

Pada Reza Homemade sistem penjualan produknya masih mengalami kendala dalam pemasaran sekaligus sebagai promosi, selama ini penjualan hanya dilakukan via telpon dan instagram maupun datang langsung di tempatnya, sehingga tidak semua konsumen (masyarakat) dapat mengetahui secara luas. Adanya kemajuan teknologi dengan pemanfaatan internet memberi peluang bagi setiap usaha untuk melakukan promosi dan pemasaran yang lebih luas. Salah satunya sistem aplikasi yang berbasis android. Berikut aliran data pemasaran yang dilakukan Reza Homemade tentang produk otak-otak kering.

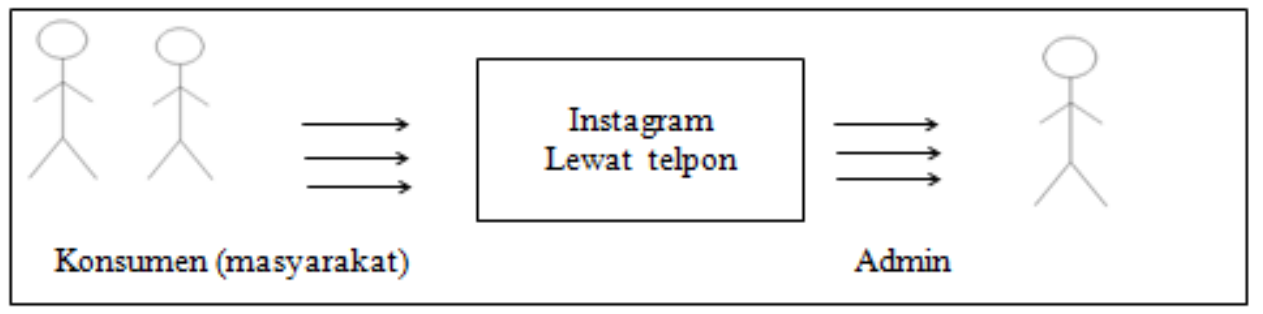

Gambar 1. Sistem Pemasaran Lama

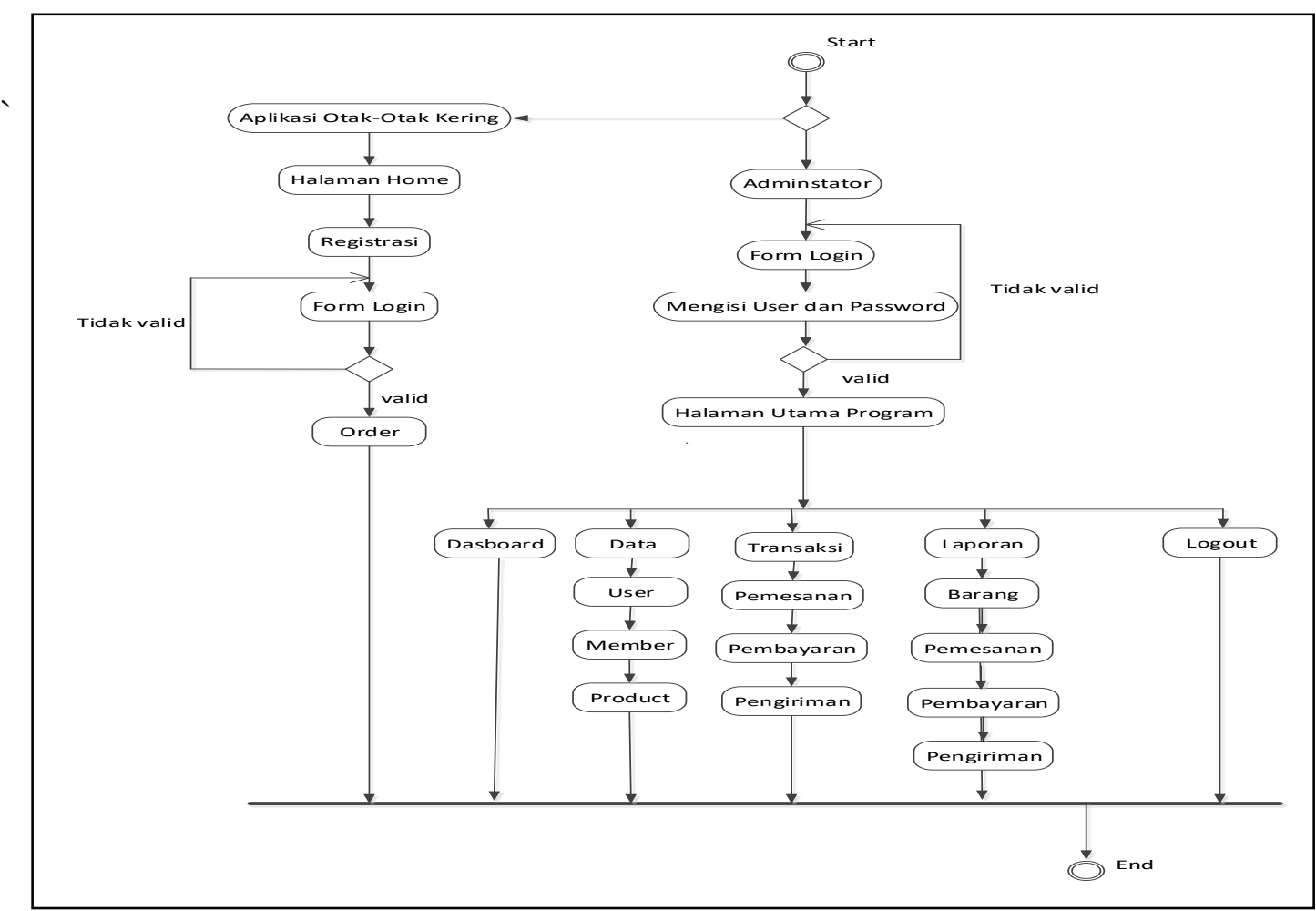

Gambar 2. Sistem Aplikasi Pemasaran Berbasis Android 
Dari gambar 1 dan 2 di atas, terlihat bahwa adanya perubahan yang dilakukan oleh Reza Homemade dalam melakuka strategi pemasaran produk otak-otak keringnya. Perubahan strategi yang dilakukan adalah pada bidang Promotion (cara promosi atau pemasaran yang dilakukan), dan Place, media sebagai tempat untuk para konsumen/masyarakat dalam mendapatkan produknya, tidak lagi dengan manual (off line) tetapi sudah secara sistem (on line) tanpa dibatasi oleh jarak dan waktu, kapan dan dimana saja. Kedua bidang tersebut merupakan bagian dari strategi Marketing Mix yang meliputi Product, Price, Promotion, dan Place.

\subsection{Perancangan Sistem}

Perancangan sistem yang digunakan dengan Unified Modelling Language (UML) akan menggambarkan secara global dan detail sistem aplikasi yang akan di bangun [9]. Pemodelan yang digunakan yaitu Use case diagram, Activity diagram, Sequence diagram dan Class diagram. Aplilkasi sistem yang dibangun memiliki dua level user yaitu admin dan pengunjung. Admin bertugas mengelola isi barang, pemesanan, pembayaran dan laporan. Perancangan sistem secara general dengan Use Case Diagran, bisa dilihat pada gambar 3, dibawah ini

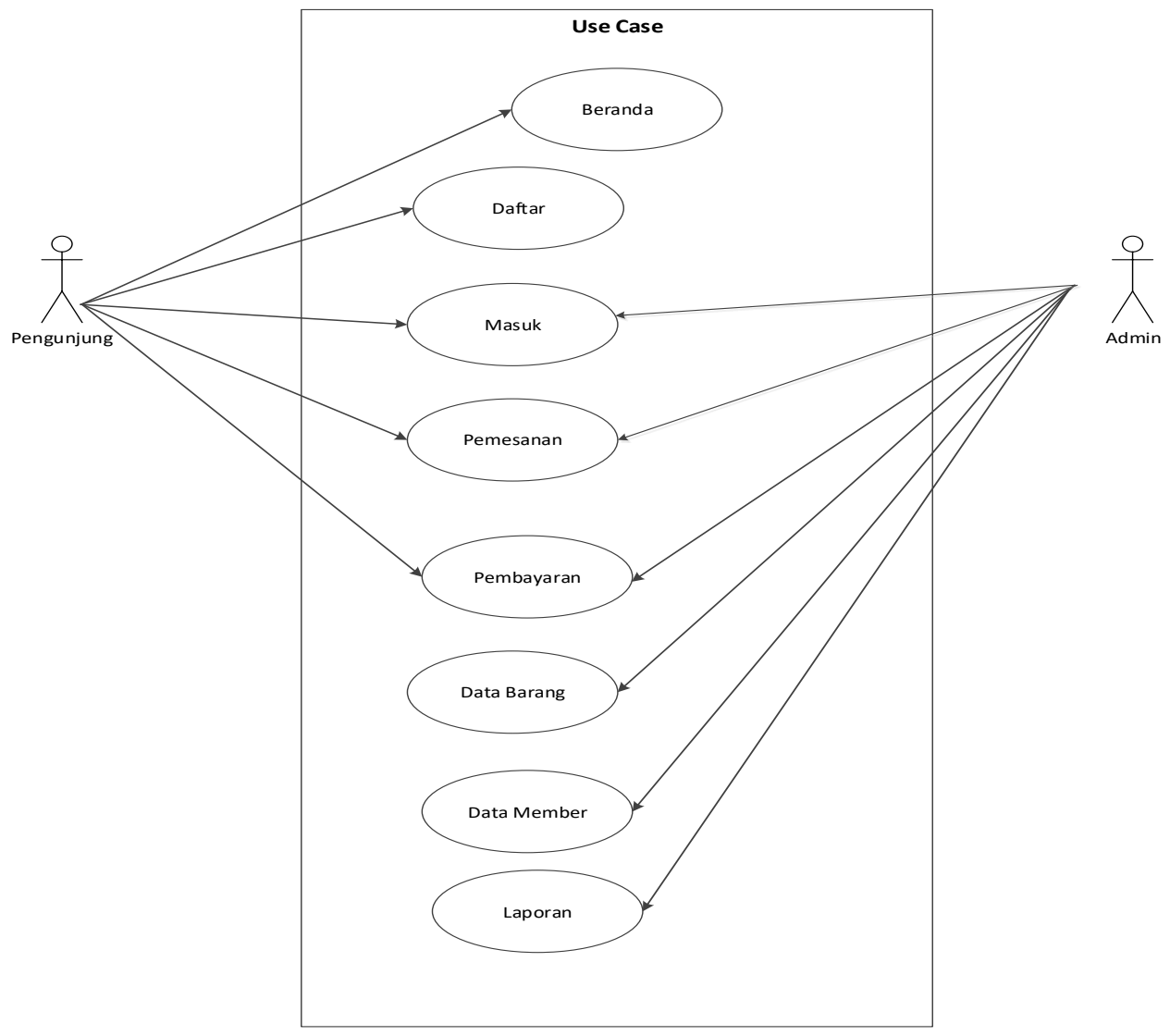

Gambar 3. Perancangan Aplikasi Pemasaran Global

Untuk perancangan secara rinci menggunakan Activity Diagram dan Sequance Diagram. Activity Diagram adalah kegiatan untuk mendeskripsikan proses atau alur kerja dari setiap proses yang dilakukan, secara detail dan lengkap, sesuai dengan implementasi aplikasi sistemnya. Activity Diagram ini meliputi kegiatan pendaftaran untuk anggota (pengunjung)/konsumen, pengguna sistem (user), daftar produk, pemesanan dan untuk transaksi pembayaran. Sementara Sequance Diagram, menjelaskan tentang tahapan-tahapan yang harus dilalui untuk setiap aplikasi sistem yang digunakan. Adanya diagram ini akan mempermudah 
bagaimana menjalankan aplikasinya. Lebih jelasnya mengenai perancangan terinci aplikasinya, dapat dilihat pada gambar sebagai berikut :

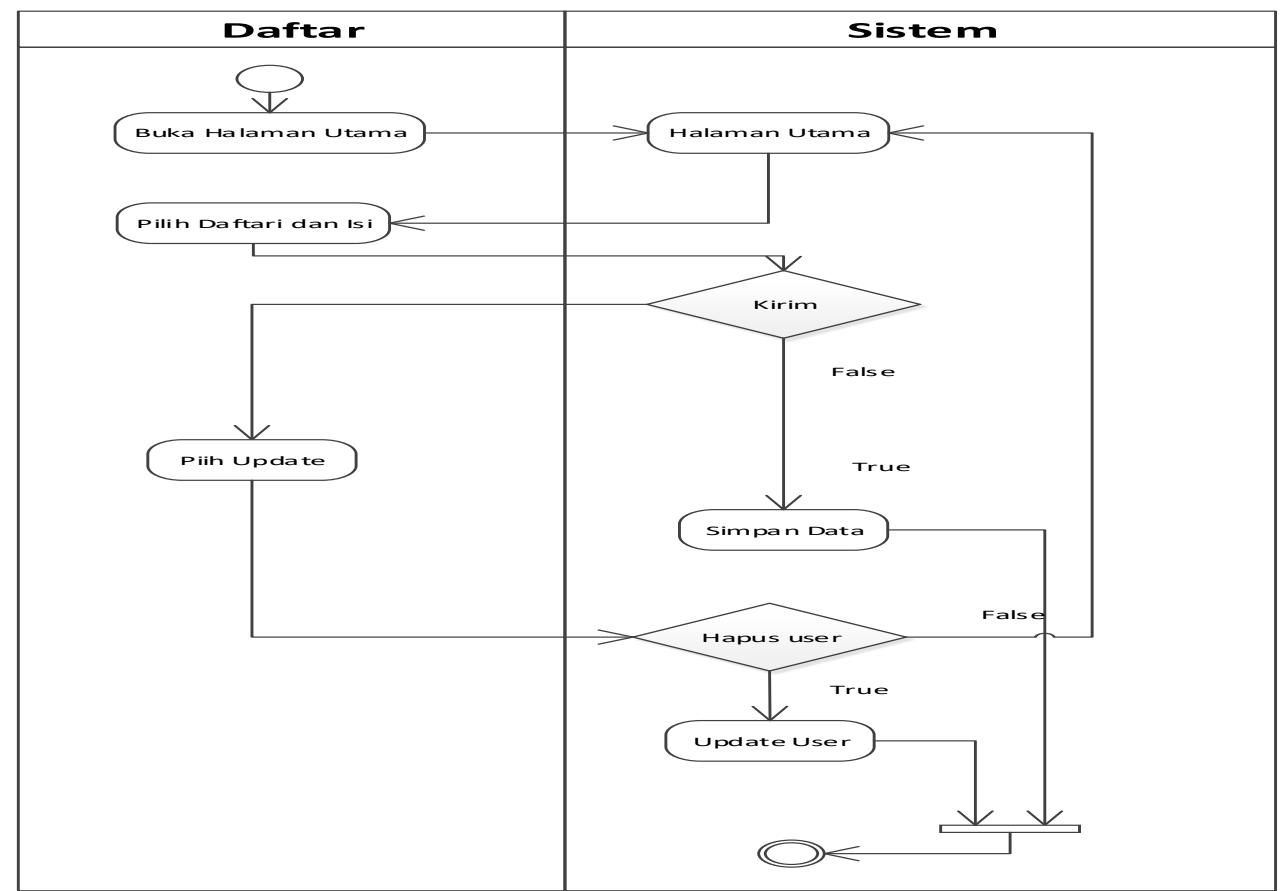

Gambar 4. Perancangan Aplikasi Pemasaran Pendaftaran Pengunjung

Dari gambar tersebut dapat dilihat bahwa pengunjung aplikasi melakukan daftar untuk dapat melakukan pemesanan atau order produk makanan otak-otak kering. Setelah pengunjung melakukan daftar akan mendapatkan user dan password sebagai member. Selanjutnya Pengguna sistem atau user untuk masuk dalam aplikasi harus memiliki user login dan password yang valid atau yang terdaftar dalam record tabel user. Apabila tidak tervalidasi atau tidak sama ada pemberitahuan login tidak berhasil dan silahkan ulang, dan apabila berhasil akan masuk ke dalam program aplikasi sesuai dengan hak akses masing-masing user, seperti Activity Diagram berikut ini :

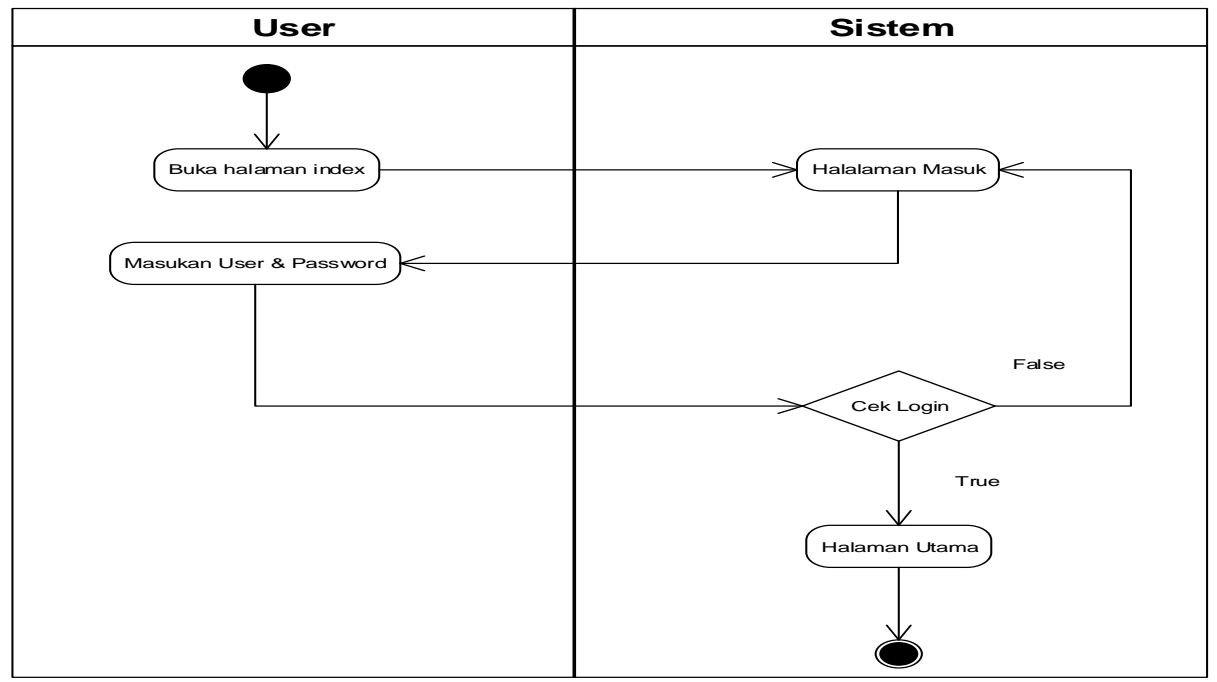

Gambar 5. Perancangan Aplikasi Pemasaran login

Setelah pengunjung (konsumen) yang telah melakukan pendaftaran dan memiliki password, maka sudah bisa untuk melakukan pemesanan produk-produk (barang) yang diinginkan. Pada saat mau melakukan pemesanan barang, maka harus login terlebih dahulu ke 
sistem dengan password yang sudah ada sebelumnya, dan ini harus benar tidak boleh salah. Untuk lebih jelasnya dapat dilihat pada gambar Activity Diagram berikut ini :

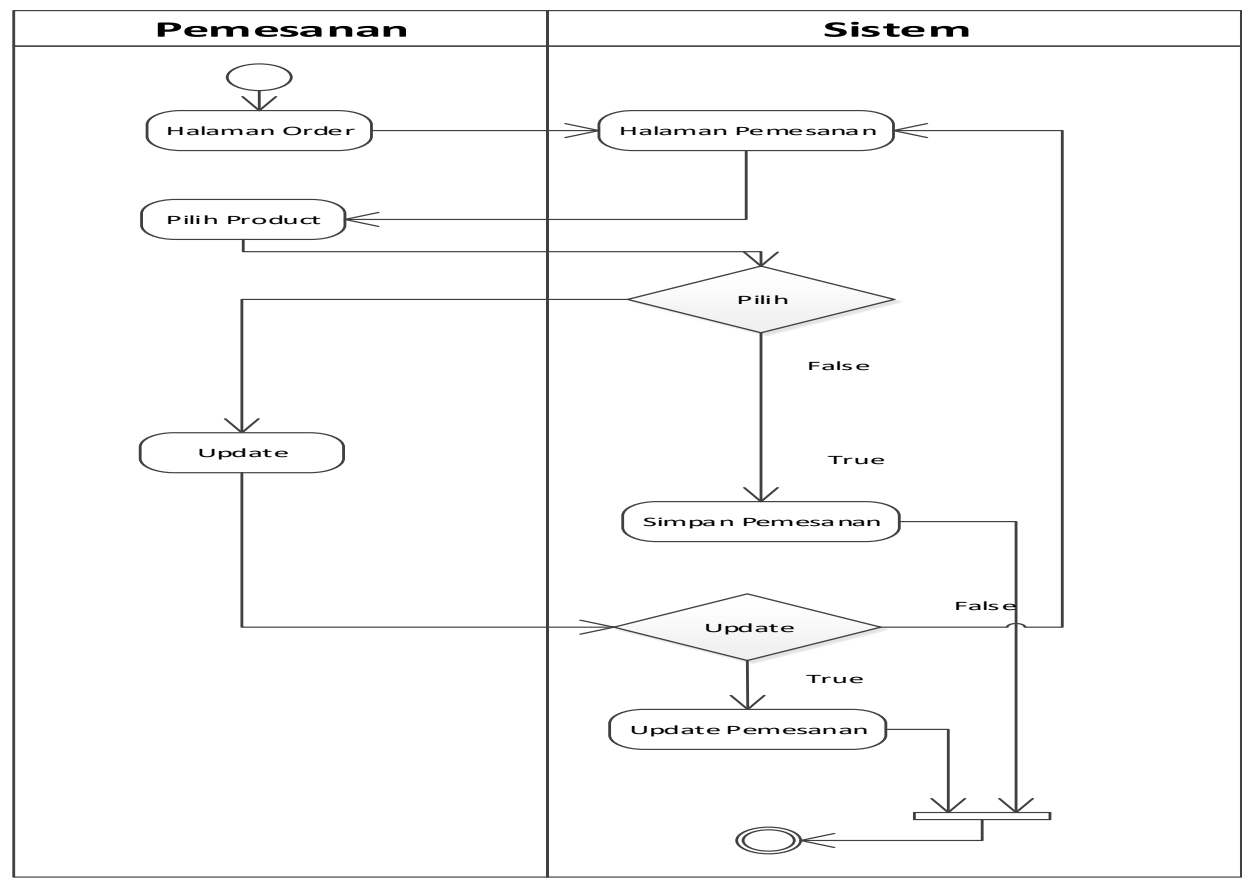

Gambar 6. Perancangan Aplikasi Pemasaran Pemesanan

Sequence Diagram yang menggambarkan alur pengguna saat melakukan masuk (login). Inputkan user name dan password kemudian login setelah itu sistem akan memverifikasi masuk (login). Jika login salah maka sistem akan mengkonfirmasikan kesalahan kepada pengguna dan meminta pengguna untuk login kembali. Kemudian pengguna melakukan login kembali dengan menginput username dan password. Apabila login sudah benar maka sistem akan masuk kehalaman utama masing-masing pengguna tergantung status atau level dari pengguna. Kemudian kalau sebagai admin, bisa melakukan kegiatan untuk tambah data, perbaikan, hapus dn lainnya. Sequence Diagram aplikasi pemasaran otak-otak kering dengan strategi Marketing Mix berbasis android, dapat dilihat pada gambar 7 sebagai berikut :

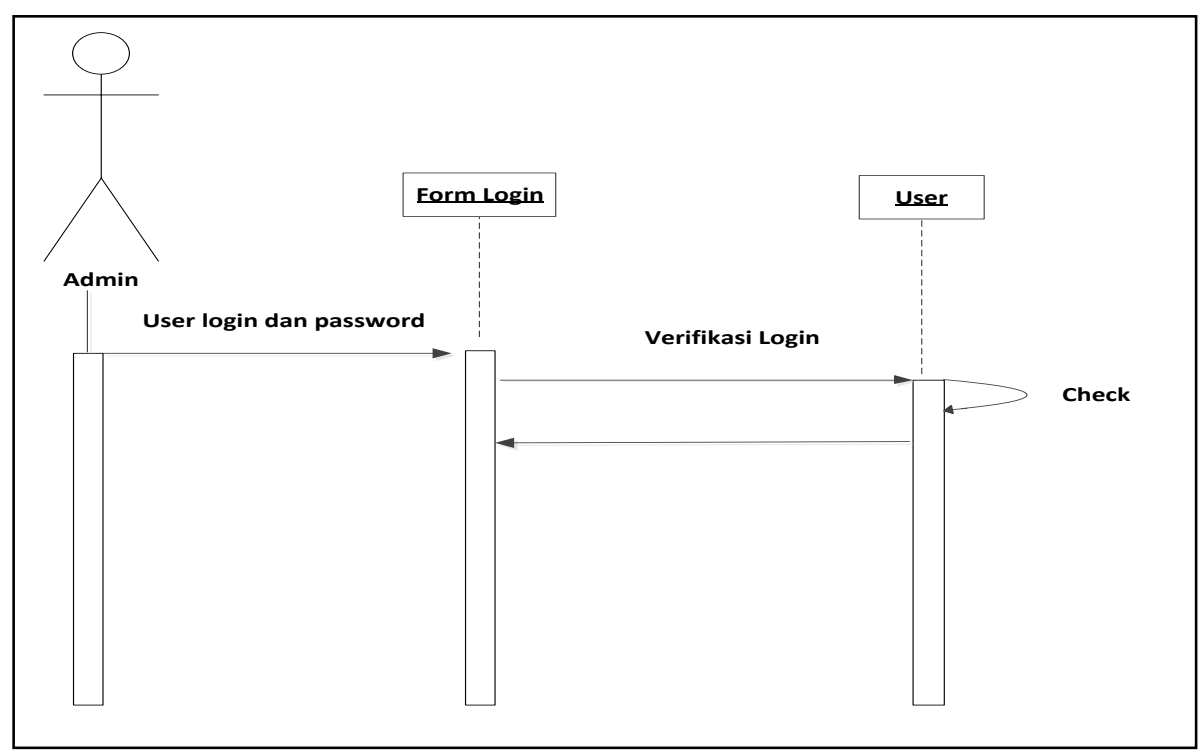

Gambar 7. Sequence Diagram Perancangan Aplikasi Pemasaran Login 


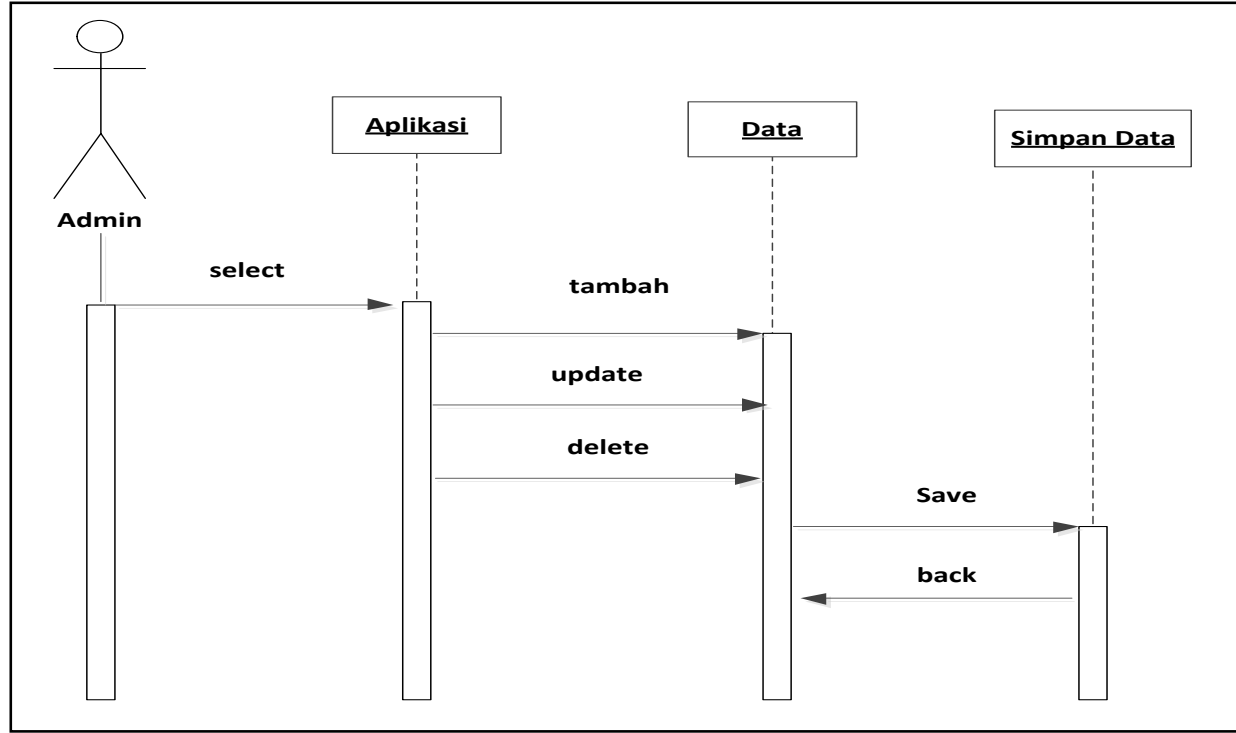

Gambar 8. Sequence Diagram Perancangan Aplikasi Pemasaran Update

Untuk melakukan kegiatan masuk data, tambah maupun transaksi, dimana sejumlah data-data akan disimpan dan diperbaiki (update), maka perlu suatu databaase yang harus dipersiapkan terlebih dahulu. Aplikasi pemasaran ini memerlukan 4 (empat) buah tabel dengan 1 (satu) database. Perancangan databasenya dapat dijabarkan dalam bentukgambar Class Diagram sebagai beikut :

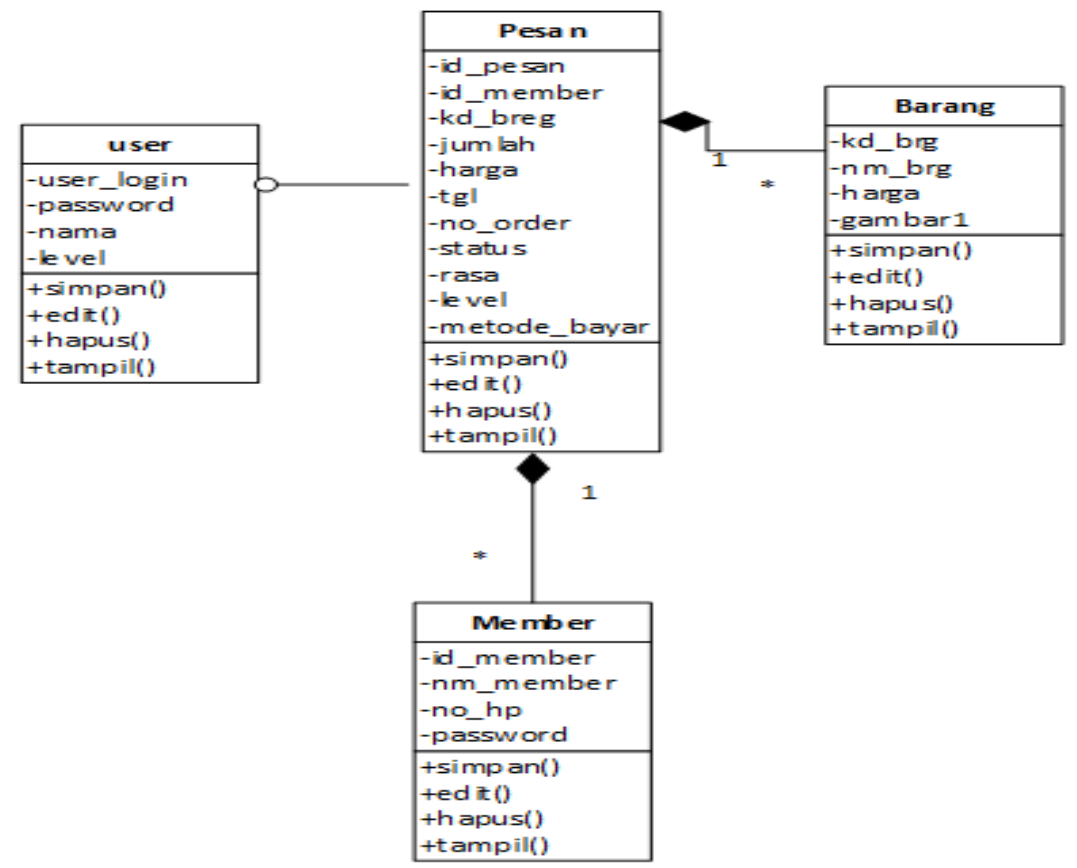

Gambar 9. Class Diagram Perancangan Aplikasi Pemasaran

\section{Hasil dan Pembahasan}

Aplikasi pemasaran otak-otak kering bisa dijalankan dengan ponsel Android, namun sebelumnya harus dilakukan penginstallan programnya terlebih dahulu. Dalam melakukan penginstallan aplikasinya harus menyesuaikan dengan kebutuhan sistem yang sudah ditentukan sebelumnya. Setelah selesai bari aplikasi pemasaran siap untuk digunakan. Pertama sekali yang harus dilakukan adalah login sistem aplikasinya. Setelah login berhasil maka akan tertuju 
kehalaman home. Halaman home memiliki beberapa menu yaitu data, transaksi, laporan dan logout untuk lebih lengkapnya dapat dilihat dari gambar 10 berikut ini.
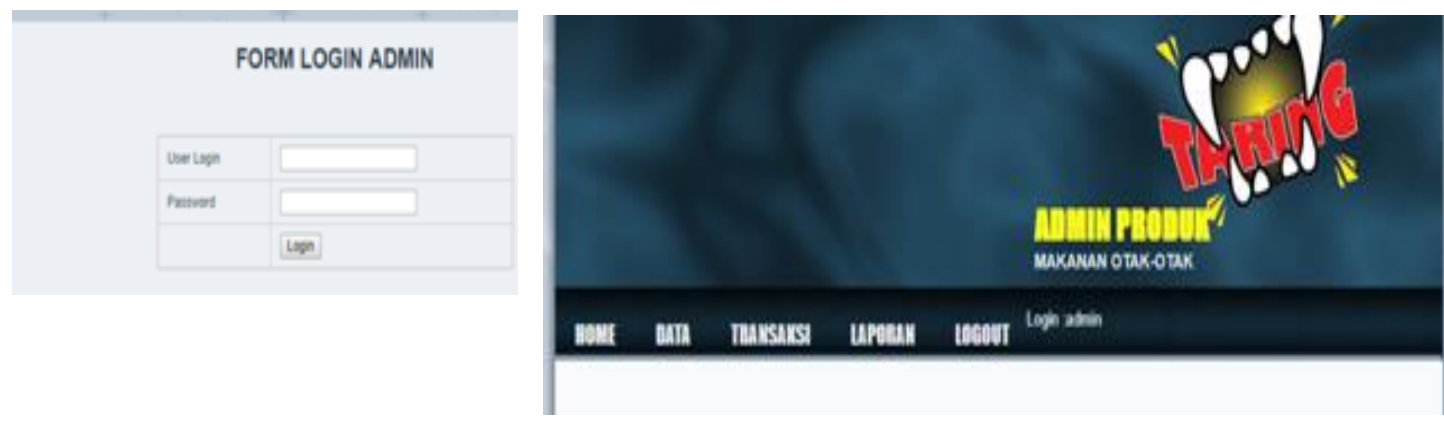

Gambar 10. Aplikasi Pemasaran Form Login dan Home

Kemudian pada menu data barang dapat melihat informasi mengenai barang yang akan dipasarkan serta admin bisa menambahkan produk atau barang. Untuk melakukan tambah produk yang dipasarkan, dapat dilihat pada gambar 11 :

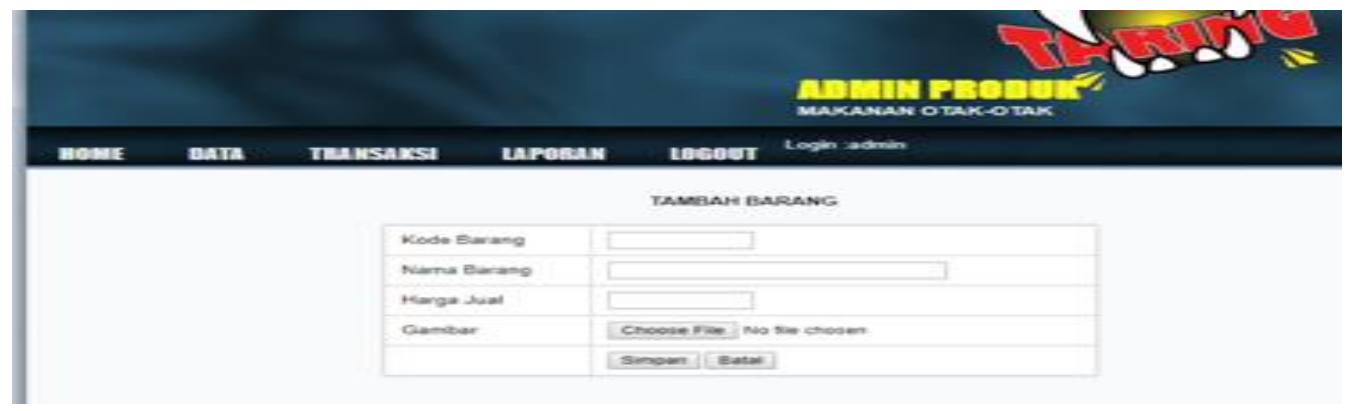

Gambar 11. Aplikasi Pemasaran memasukkan Produk

Selanjutnya akan bisa dilihat daftar sejumlah produk (barang) yang sudah siap untuk dipesan oleh konsumen. Konsumen hanya memilih produk mana yang diinginkan karen semua produk sudah ditampilkan, lengkap dengan penjelasannya seperti gambar berikut :

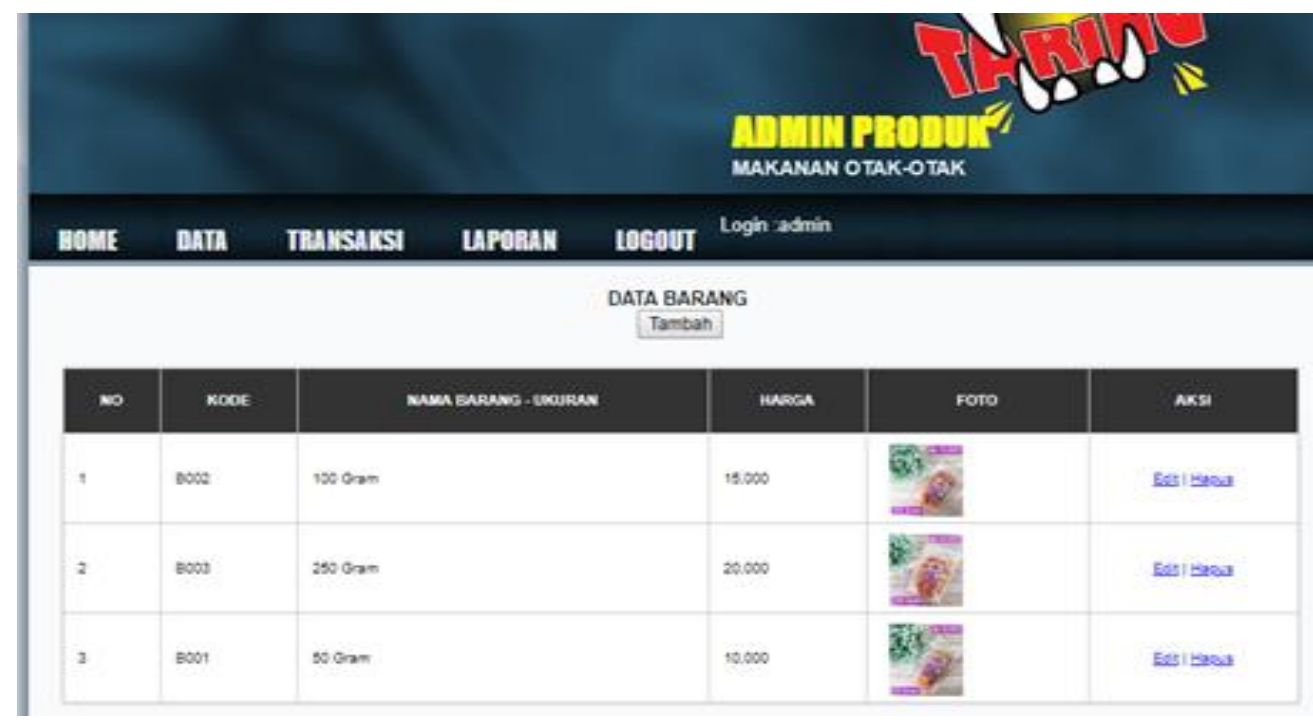

Gambar 12. Aplikasi Pemasaran Produk 
Untuk tampilan yang dihasilkan pada ponsel android, dapat diuraikan bahwa, tampilan beranda dari aplikasi ada beberapa menu utama seperti petunjuk, daftar, masuk dan product, yang dapat dilihat dari gambar berikut ini
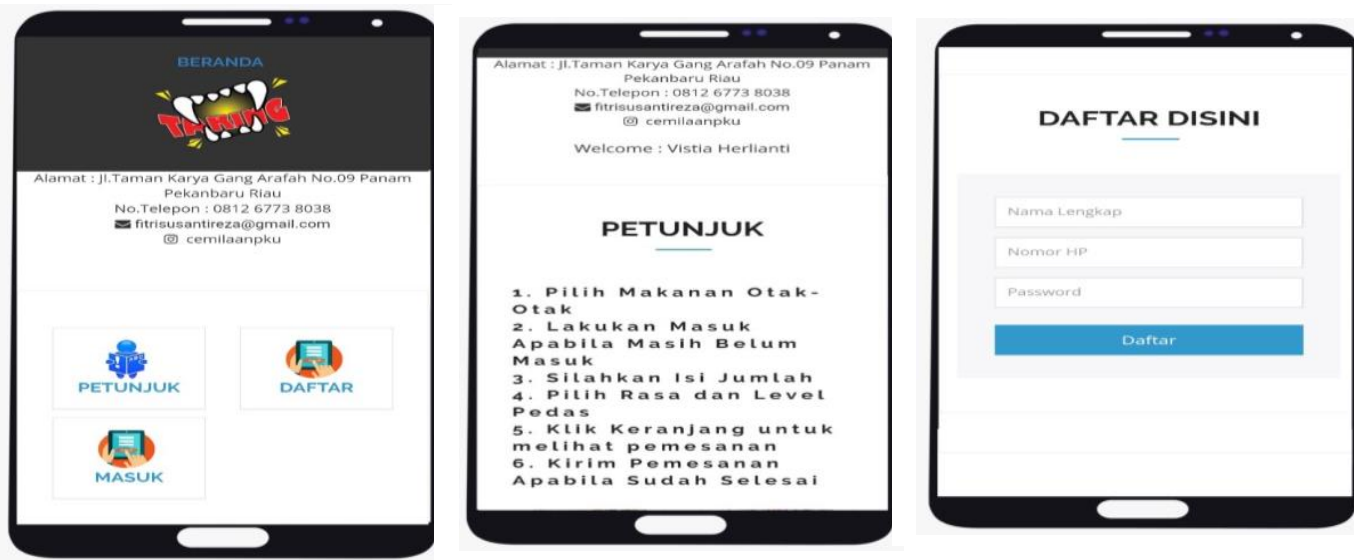

Gambar 13. Tampilan Aplikasi Pemasaran Pada Sistem Android

Pada tampilan info dari menu utama, memberikan informasi mengenai kegiatan transaksi yang dilakuka. Jika belum melakukan transaksi maka tampilan akan kosong namun jika sudah melakukan transaksi maka muncul info transaksinya,seperti dapat dilihat dari gambar berikut ini.
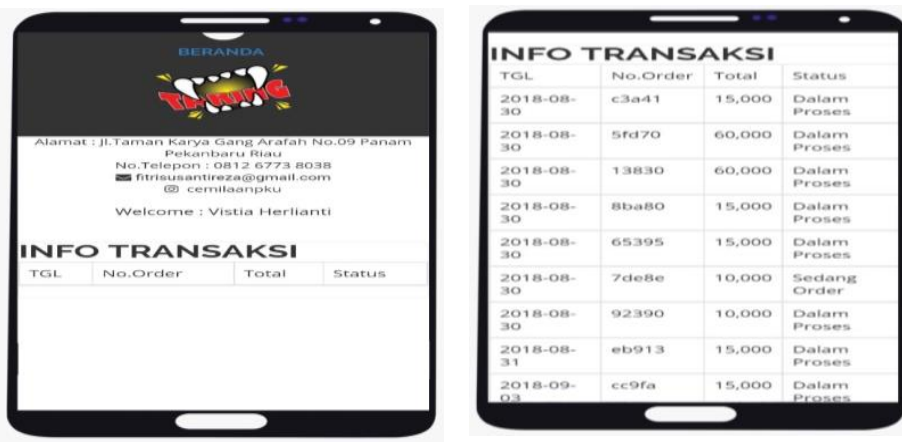

Gambar 14. Transaksi Aplikasi Pemasaran Pada Sistem Android

Pada sistem android bisa jua menampilan beberapa produk otak-otak kering dari menu utama. Dimana kita bisa memilih yang mau dipesan, hanya mengisi jumlahnya, aneka rasa dan level yang akan kita pesan. Lebih lengkapnya dapat dilihat dari gambar berikut ini.
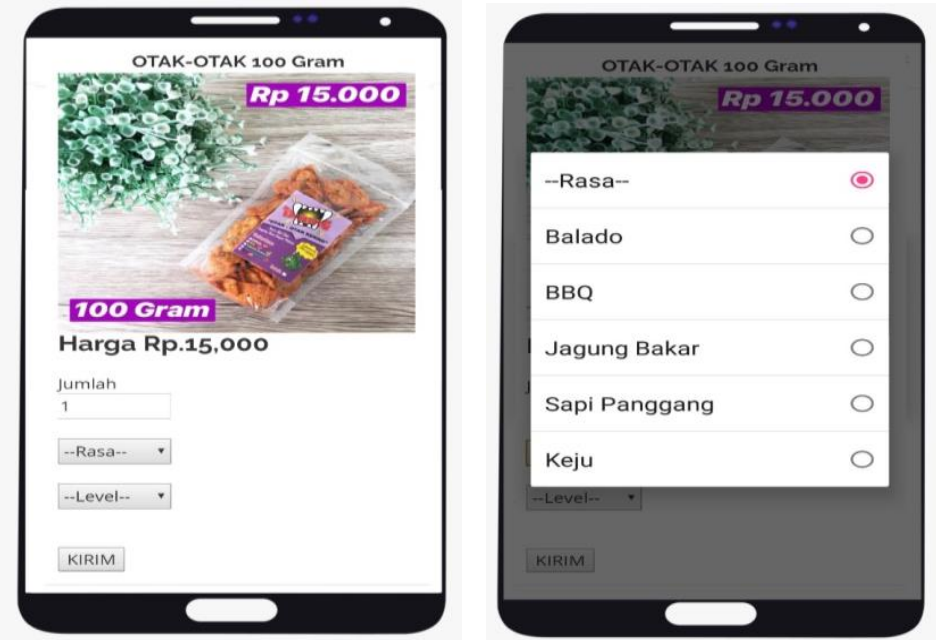

Gambar 15. Aplikasi Pemasaran Pemilihan produk 
Setelah melakukan pemilihan pembayaran dan melakukan pembayaran secara tunai ataupun transfer bukti. Setelah kirim bukti transfer pada whatapps yang tertara pada alamat kantor, hingga barang bisa diantar. Setelah klik kirim maka secara otomatis akan logout account dan menampilkan tampilan sebagai berikut :

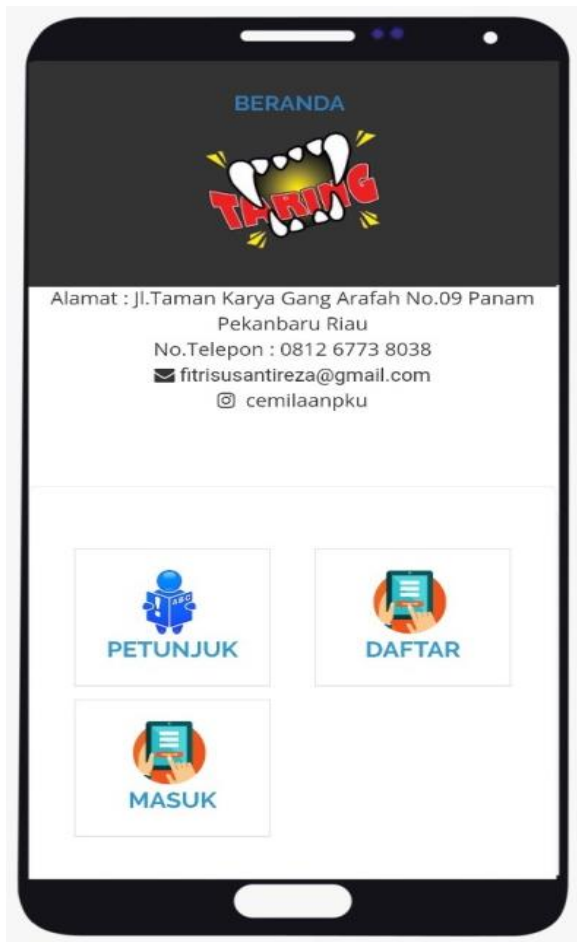

Gambar 16. Aplikasi Pemasaran logout account

Dalam melakukan implementasi aplikasi pemasaran otak-otak kering, maka perlu dilakukan pengujian terhadap aplikasi sistem yang sudah selesai. Pengujiam aplikasi ini menggunakan Black Box sesuai dengan perancangan sistem serta sekaligus sebagai pembanding apakan sudah sesuai, jika belum tentunya akan dilakukan perbaikan atau penyesuaian lagi sehingga menghasilkan allikasi sistem sesuai dengan rancangannya. Pengujian aplikasi pemasaran ini, dilakukan terhadap pengunjung (konsumen), admin, proses transaksi dan keluarannya (hasil). Lebih jelasnya dapat dilihat pada tabel-tabel berikut :

Tabel 1. Pengujian Konsumen

\begin{tabular}{|l|l|c|}
\hline \multicolumn{1}{|c|}{ User } & \multicolumn{1}{|c|}{ Aktifitas } & Status \\
\hline Pengunjung & 1. Daftar & 2. Masuk \\
& 3. Pemesanan & 4. Pembayaran \\
\hline
\end{tabular}

Pada pengujian Tabel 1 di atas, menjelaskan bahwa untuk setiap user (pengunjung) yang melakukan aktifitas daftar, masuk, pemesanan dan pembayaran semua berhasil dengan baik. 
Tabel 2. Pengujian Admin

\begin{tabular}{|l|l|c|}
\hline \multicolumn{1}{|c|}{ User } & \multicolumn{1}{|c|}{ Aktifittas } & Status \\
\hline Admin & 1. Login & \\
& 2. Tambah Barang & \\
\hline
\end{tabular}

Untuk Tabel 2 di atas, menjelaskan kegiatan admin dalam melakukan aktifitasnya, yang berhubungan login dan penambahan setiap barang yang dimasukkan ke dalam sistem aplikasi pemasaran juga berhasil dengan baik.

Tabel 3. PengujianTransaksi

\begin{tabular}{|l|l|c|}
\hline \multicolumn{1}{|c|}{ User } & \multicolumn{1}{|c|}{ Aktifitas } & Status \\
\hline Proses & 1. Pemesanan & \\
& 2. Pembayaran & \\
& 3. Pengiriman & \\
\hline
\end{tabular}

Pada Tabel 3 di atas, yang merupakan aktifitas user untuk setiap kegiatan transaksi/proses yang dilakukan, setelah dilakukan pengujian semuanya berhasil dengan baik (sukses). Aktifitas prosesnyam eliputi pemesanan, pembayaran dan pengiriman.

Tabel 4. Pengujian Proses (Hasil)

\begin{tabular}{|l|l|l|}
\hline \multicolumn{1}{|c|}{ User } & \multicolumn{1}{|c|}{ Aktifitas } & Status \\
\hline Output & 1. Laporan Pemesanan & \\
Harian & 2. Laporan Pemesanan & \\
Bulanan & \\
3. Laporan Pembayaran & \\
Harian & 4. Laporan Pembayaran & \\
& Bulanan & \\
5. Laporan Pembayaran & \\
& Pengiriman Harian & \\
& 6. Laporan Pembayaran & \\
Pengiriman Bulanan & \\
& \\
\end{tabular}

Tabel 4 di atas adalah tabel yang menjelaskan pengujian untuk pelaporan (hasil) dari semua kegiatan yang telah dilakukan. Laporan yang dihasilkan menakup laporan pemesanan harian, pemesanan bulanan, laporan harian, pembayaran bulanan, laporan pembayaran pengiriman harian dan laporan pembayaran pengiriman bulanan.

\section{Kesimpulan}

Pembuatan aplikasi pemasaran otak-otak kering menggunakan strategi Marketing Mix atau sering disebut juga dengan berbaur pemasaran berbasis android, dapat memberikan wawasan baru pada dunia pendidikan, khususnya bagi para pengembang/programmer khusus yang berbasiskan Android ke depannya. Adanya aplikasi sistem yang dibangun juga mempermudah kinerja Reza Homemade dalam memasarkan otak-otak kering lebih luas lagi jangkauannya dan memudahkan akses konsumen dalam melakukan pemesanan maupun pembayaran serta mengenalkan produknya lebih luas lagi.. 


\section{Daftar pustaka}

[1] R. rans Fela, "Promosi Makanan Khas Indonesia Melalui Wirausaha Jasa Berbasis," Fak. Teknogi Pertanian-UGM, vol. 2, pp. 1-6, 2014.

[2] H. (Universitas B. N. Hartono, K. (Universitas B. N. Hutomo, and M. (Universitas N. Mayangsari, "PENGARUH STRATEGI PEMASARAN TERHADAP PENINGKATAN PENJUALAN PADA PERUSAHAAN " DENGAN MENETAPKAN ALUMNI DAN MAHASISWA UNIVERSITAS BINA NUSANTARA SEBAGAI OBJEK PENELITIAN Hendry Hartono ; Karyana Hutomo ; Marshelia Mayangsari," Binus Bus. Rev., vol. 3, no. 2, pp. 882-897, 2014.

[3] A. Juansyah, "PEMBANGUNAN APLIKASI CHILD TRACKER BERBASIS ASSISTED - GLOBAL POSITIONING SYSTEM ( A-GPS ) DENGAN PLATFORM ANDROID Jurnal Ilmiah Komputer dan Informatika ( KOMPUTA )," J. Ilm. Komput. dan Inform., vol. 1, no. 1, pp. 1-8, 2015.

[4] A. A. Lumintang, "Marketing Mix Pengaruhnya TLumintang, A. A. (2013). Marketing Mix Pengaruhnya Terhadap Loyalitas Konsumen Sabun Mandi Lifebuoy di Kota Manado. Jurnal Emba, 1(3), 140-150.erhadap Loyalitas Konsumen Sabun Mandi Lifebuoy di Kota Manado," J. Emba, vol. 1, no. 3, pp. 140-150, 2015.

[5] K. Keller, Manajemen Pemasaran. 2016.

[6] D. Pada, P. T. Astra, I. Manado, F. Ekonomi, and J. Manajemen, "2872-5327-1-Sm," vol. 1, no. 4, pp. 1134-1144, 2015.

[7] Lily, "Pengolahan otak-otak kering ikan Lele dengan memanfaatkan wortel Out ogg Grade," J. Peneltian Politek. Negeri Payakumbuh, vol. 15, no. 1, 2016.

[8] M. N. Amelia, Y. E. Prasetyo, 11, 1, and I. Maharani, "E-UMKM: APLIKASI PEMASARAN PRODUK UMKM BERBASIS ANDROID SEBAGAI STRATEGI MENINGKATKAN PEREKONOMIAN 21 Meri Nur Amelia Fakultas Teknik Universitas Muria Kudus 1* INDONESIA,” vol. 4, pp. 91-96, 2017.

[9] W. Aprianti and U. Maliha, "Sistem Informasi Kepadatan Penduduk Kelurahan Atau Desa Studi Kasus Pada Kecamatan Bati-Bati," vol. 2, no. 2013, pp. 21-28, 2016.

[10] D. Aplikasi and M. Informasi, "JALUR BATIK SOLO TRANS BERBASIS ANDROID," vol. 6, no. April, pp. 46-55, 2017. 